\title{
AC 2008-1686: CURRICULUM DEVELOPMENT FOR A NEW ENERGY ENGINEERING MAJOR
}

Sarma Pisupati, Pennsylvania State University

Yaw Yeboah, Pennsylvania State University, University Park 


\title{
Curriculum Development for a New Energy Engineering Major at The Pennsylvania State University
}

\begin{abstract}
With the world's thirst for energy continuing to grow, there is now an urgent demand for a well trained workforce to develop, process, utilize and manage conventional, unconventional, and renewable energy sources in an environmentally safe and economically feasible way. To move The Pennsylvania State University to the forefront in energy, the Department of Energy and Mineral Engineering developed for the first time in the US, a formal undergraduate degree program (Bachelor of Science) in the growing field of energy engineering. Through collaboration and cooperative arrangements with other departments and colleges, and flexibility in the program, science and engineering students with special interests in energy would be able to obtain a BS degree in Energy Engineering on its own or dual/concurrent degrees, minors, options or general education in energy engineering. Along with the basic engineering skills, the program integrates skill sets in the physical sciences (chemistry, engineering, mathematics, and physics) and social sciences (economics, policy, and management).

The first two years of the program are similar to traditional engineering disciplines. Thereafter, one takes a series of courses that introduce Energy Engineering concepts. Fundamental energy engineering principles involve material and energy balances, thermodynamics, fluid mechanics, heat and mass transfer operations, and physical and chemical processing as applied to energy industries. In addition to these engineering principles, students enroll in required courses in renewable/sustainable energy principles. Students will be trained in basic chemistry of fuels - coal, petroleum, natural gas and biomass; combustion; petroleum and natural gas processing; electrochemical energy conversion; and energy conversion processes including chemical, nuclear, biological and catalytic. Students also choose departmental electives from courses such as green energy engineering and environmental compliance, hydrogen and fuel cell technology, materials for energy applications, physical processes in energy engineering, and air pollutants from combustion sources. Professional electives allow students to gain exposure to business, legal and ethical issues related to energy. Technical electives can be chosen to provide specialization or breadth and depth in renewable or non-renewable energy and/or mechanical or chemical aspects of energy.

This paper discusses the program, the rationale in developing the program, and the details of the novel curriculum.
\end{abstract}

\section{Introduction}

World population and energy consumption both continue to grow significantly. Also, due to global uncertainties, energy is becoming increasingly important. The United States, for example, increasingly relies on imported energy (32.9\% in 2006) ${ }^{1}$. Projections from DOE's Annual Energy Outlook indicate that primary energy use in the United States will climb to 134 Quadrillion Btu in 2030 from 98 in $2000^{2}$. Despite increases in electricity generation efficiencies, total electricity consumption is also predicted to increase. President Bush has called for an Advanced Energy Initiative based on the development of hydrogen fuel, clean coal technologies, cellulose-based ethanol, solar and wind energies, and advanced automotive batteries. 
Concurrently, there is an aging workforce. Refinery operations are very close to maximum capacity and any terrorism or natural disasters could weaken our ability to ensure an affordable supply of energy. New challenges, such as converting coal and gas to liquids, transporting more fuel across the nation as gas, liquid or electricity, and extracting and converting non-traditional (renewable) fuel sources, are facing the energy industry.

\section{Rationale}

To meet the increasing energy demand, the nation and the world will require a well trained diverse workforce to develop process, utilize and manage conventional, unconventional and renewable energy sources in an environmentally safe and economically viable manner. Unfortunately, many of the academic programs that provided such workforce have either closed (e.g., petroleum and mining engineering programs) or redirected their focus to the health or biorelated areas (e.g., chemical engineering) leaving many energy producing and consuming industries with an aging technical workforce and growing workforce demand. There is also renewed emphasis on the development of alternative sources of energy to conventional fossil fuels. The increasing demand for energy and trained energy workforce calls for innovative methods to increase enrollments and graduation rates of students in energy-focused disciplines. Such a workforce is essential for the future of America, our energy security, and is a strategic issue of great importance to the nation.

With society's growing need for energy and energy-related workforce, many institutions are vying to take advantage of these opportunities and challenges. Many academic institutions with traditional engineering programs (e.g., chemical, civil, mechanical, electrical and nuclear engineering) have also created departments and/or programs in energy engineering to reflect the growing need and trend. To move The Pennsylvania State University to the forefront in energy, the Department of Energy and Mineral Engineering proposes a formal undergraduate degree program (Bachelor of Science) in the growing field of energy engineering. The program will be beneficial to students of several colleges at The Pennsylvania State University. Through collaboration and cooperative arrangements with other departments and colleges, and flexibility in the program, science and engineering students at The Pennsylvania State University with special interests in energy would be able to obtain dual or concurrent degrees, minors, options or general education in energy engineering.

The plans for this program which were initiated in Fall 2005, are consistent with the recently released University Energy Task Force report and the recommendation for the University to "develop an exciting new undergraduate and graduate curriculum in energy". The undergraduate program in energy engineering is designed to reflect the growing impact and demand for energy in society and to equip students with the knowledge necessary to achieve the following career and professional accomplishments or program educational objectives: become valuable contributors in addressing society's energy needs and demands; successful leaders in advancing the technology and management of energy; innovators and entrepreneurs in the energy sector; and educators, practicing engineers, and national leaders on energy and associated environmental, health and safety, and policy and economics issues. The program integrates skill sets in the physical sciences (chemistry, engineering, mathematics and physics) and social sciences (economics, policy, and management) to ensure successful career opportunities and growth within energy-related industries, government agencies, and academia. 
The courses are structured to enable students to understand engineering fundamentals and apply the knowledge to solve problems in the production, processing, storage, distribution, and utilization of energy using multiple techniques as synthesis, analysis, design and case studies. Inquiry-based teaching methods and lab experiences are emphasized. The faculty research and scholarly activities are integrated into the curriculum. The program is designed to train students to be lifelong learners, problem solvers, and energy industry leaders. The educational opportunities are sufficiently flexible, broad, and diverse to enable students to tailor their educational experience to particular interests, background, and expected role in society. Flexibility in the curriculum allows other students in energy related programs such as agricultural and biological, chemical, civil, electrical, environmental, mechanical, mining, nuclear, and petroleum engineering, materials science and engineering, industrial health and safety, and energy business and finance to have dual or concurrent degrees, minors, or options (e.g., energy and fuels engineering option in chemical engineering).

\section{Review of Programs}

Many academic institutions with traditional engineering programs (e.g., chemical, civil, mechanical, electrical and nuclear engineering) have also created departments and/or programs in energy engineering to reflect the growing need and trend. Among these are:

- Department of Energy and Geo-Environmental Engineering at Penn State

- Energy Science and Engineering track in the Mechanical Engineering Department at the Massachusetts Institute of Technology (MIT)

- Department of Energy Resources Engineering (formerly Department of Petroleum Engineering) at Stanford University

- Energy Engineering program at the University of Massachusetts, Lowell

- Mechanical and Energy Engineering Department at University of North Texas

- Sustainable Energy Engineering program at Florida State University.

- Bachelor of Science in Renewable Energy Systems at Oregon Tech, Portland, Oregon

- Division of Environment and Energy Engineering at University of Hyogo, Japan

- Department of Energy and Hydrocarbon Chemistry, Kyoto University, Japan

- Department of Energy Engineering and Science at Nagoya University, Japan

- Department of Quantum Science and Energy Engineering at Tohoku University, Japan

- Department of Energy and Environmental Engineering at Kyushu University, Japan

- Environmental Energy Engineering, Musashi Institute of Technology, Japan

- Sustainable Energy Engineering program within the Department of Energy Technology at the Royal Institute of Technology, Sweden

- Section of Energy Engineering at the Technical University of Denmark

- Sustainable Energy Engineering in the Department of Energy Technology at Aalborg University, Denmark

- Energy Engineering in the Mechanical and Energy Engineering department at Leipzig University of Applied Sciences, Germany

- Energy Engineering program at Aachen University, Germany

- Department of Energy and Process Engineering at the Norwegian University of Science and Technology, Norway

- Department of Power and Energy Engineering, Shanghai Jiaotong University, China

- Energy Engineering program at the University of Dar Es Salaam, Tanzania 


\section{Program Objectives:}

The integration of knowledge and skills acquired should enable graduates of the program to accomplish the following program educational outcomes:

1. Solve energy and associated environmental problems using the fundamental knowledge in basic mathematical, chemical, physical, and social sciences learned.

2. Design and conduct experiments, acquire data, and define, analyze, and interpret data, and solve practical, complex, energy engineering problems.

3. Integrate professional, ethical, social and environmental factors in energy engineering design and problem solving and understand the impact of these factors on global energy issues.

4. Develop the ability to communicate effectively in writing and orally and build teamwork.

5. Acquire the desire for lifelong learning to maintain technical competence and keep abreast of new developments in the field.

\section{Curriculum}

The sequences of courses required for the BS in energy engineering degree are outlined in Table 1. Students may select their Departmental, professional, and technical electives from a list that includes courses from Chemical, Mechanical, Electrical, Nuclear, Agricultural and Chemistry departments. The technical electives are energy-related courses outside the major that are offered by various colleges across The Pennsylvania State University. Substitutions must be made by petition.

\section{Curriculum Approval Process}

A dynamic curriculum, one undergoing constant review and revision, constitutes the heart of an institution of higher education. Courses and programs are initially developed and proposed by faculty, once approved by the Senate Committee on Curricular Affairs (SCCA), the Graduate Council, or any unit with delegated curricular authority on behalf of the faculty of the University, these courses/programs become University courses and programs. Subsequent changes and the monitoring of the quality of the curriculum become the responsibility of the appropriate disciplinary faculty throughout the University with final approval resting with the SCCA. 


\section{Semester}

CHEM 12 (GN) Chemical Principles

CHEM 14 (GN) Experimental

Chemistry

MATH 140 (GQ) Calculus With

Analytic Geometry I

EM SC 100S (GWS) Freshman Seminar *

ECON 02/14 or ENNEC 100 (GS)

Economics (GA/GH/GS Elective 1)

Health and Physical Activity (GHA)

\section{3rd Semester}

CHEM 38 Organic Chemistry

MATH 251 Ordinary and Partial Differential Equations

PHYS 212 (GN) General Physics: Electricity And Magnetism

GA/GH/GS Elective 3

GA/GH/GS Elective 4

\section{5th Semester}

EGEE 012 Energy Engineering Lectures

MATSE 201 Intro. to Material Science

EGEE 301 Thermodynamics and Fluid Mechanics of Energy Systems

EGEE 302 Principles of Energy

Engineering

Professional Elective 1

\section{7th Semester}

ENGL 202C (GWS) Technical Writing

FSC 432 Petroleum and Natural Gas Processing

EGEE 441 Electrochemical Energy Conversion

EGEE 451 Energy Conversion Processes: Chemical and Nuclear IE 302 Engineering Economy or PNG 489 Engineering Evaluation Technical Elective 1

Table 1

Bachelor of Science in Energy Engineering Program

\section{2nd Semester}

CHEM 13 (GN) Chemical Principles

MATH 141 (GQ) Calculus With Analytic Geometry II

PHYS 211 (GN) General Physics: Mechanics

ENGL 015 (GWS) Rhetoric and Composition or ENGL 030 (GWS)

GA/GH/GS Elective 2

4th Semester

EE 220 Electrical Circuits and Power 3 Distribution*

MATH 231 Calculus of Several 2 Variables

CMPSC 201C or CMPSC 201F or EMSC 468

PHIL $103(\mathrm{GH})$ Ethics (GA/GH/GS Elective 5)

GA/GH/GS Elective 6

Health and Physical Activity (GHA)

\section{6th Semester}

EGEE 304 Heat and Mass Transfer

EGEE 430 Intro. to Combustion 3

FSC 431 Chemistry of Fuels- coal, 3 petroleum, gas, biomass

EGEE 411 Energy Laboratory

EGEE 438 Sustainable Energy Options 3

\section{8th Semester}

EGEE 494A Research Projects

EGEE 437 Fundamentals of Renewable Energy 
Students also choose electives from courses such as green energy engineering and environmental compliance, hydrogen and fuel cell technology, materials for energy applications, physical processes in energy engineering, and air pollutants from combustion sources. Professional electives allow students to gain exposure to business, legal and ethical issues related to energy. Technical electives can be chosen to provide specialization or breadth and depth in renewable or non-renewable energy and/or mechanical or chemical aspects of energy.

All students in the program take an energy engineering lab course, engage in a supervised independent research project, and participate in an integrative interdisciplinary design project/course. The design project is carried out as part of The Pennsylvania State University's Learning factory that engages students from different engineering disciplines on teams to address industrially challenging problems. This paper will discuss the new energy engineering initiative, the novel curriculum, and the seamless integration of research into the training and education of students to help to produce the next generation of skilled workforce for the energy industry.

\section{Research Integration}

Integration of research into the program is carried out at three levels: in the required energy lab class (EGEE 411); the independent research projects class (EGEE 494), and the integrative design project (EGEE 464W) course. In the energy engineering lab, students engage in lab research in fuel characterization, engine testing, boiler efficiency determination, proximate and ultimate analysis, and renewable energy efficiencies.

Research Project: The independent research project varies with the interest of the student and the expertise of the advisor. The project may cover conventional fossil fuels (coal, oil and natural gas) or renewable energy options such as solar, wind, biomass or geothermal. It may also cover unconventional sources as shale oil, tar sands, coal bed methane and methane hydrates. A student typically performs an independent research in one of these areas under the supervision of a faculty. The focus of the work may include aspects of the production, processing and utilization of energy. It may also cover the environmental, health and safety, and business/management issues. In the methodology and analysis, probability, statistics and experimental design methods may be employed. An economic evaluation of the project may also be undertaken. The student submits a final report and defends his/her work through a technical presentation on the work.

Learning Factory. The mission of The Pennsylvania State University Learning Factory is to integrate design, manufacturing and business realities into the engineering curriculum. It is an industry-university partnership that involves multidisciplinary students working on real-life industrially sponsored problems. Since 1995, over 500 sponsored projects have been completed for 140 companies. The Learning Factory was awarded the 2006 Gordon Prize by the National Academy of Engineering. The Bernard M. Gordon Prize - recognizes innovation in engineering education - "for creating the Learning Factory, where multidisciplinary student teams develop engineering leadership skills by working with industry to solve real-world problems."

The energy engineering curriculum was designed to enable students in the program to carry out their capstone design project through The Pennsylvania State University Learning Factory. The students are able to work with teams of students from chemical, mechanical and 
other engineering disciples on common energy-related problems giving them broad exposure to how they are expected to operate as part of the energy workforce.

The experiences gained from the integration of research into the curriculum, enhance students' understanding of concepts learned in the classroom, prepare students for the real life working environment, and promote teamwork. Students are better able to see the interrelationships between the disciplines and how they are expected to collaborate in industry for the common good of the company.

The capstone design course is to be a culmination of the knowledge and skills learned in earlier courses as well as a writing intensive course which means students are expected to learn to write and be given ample opportunity to practice writing. The work will culminate is a final written report and technical presentation to a public audience. The projects are judged by a panel of industry and faculty experts and awards made to the top place finishers.

\section{Minor in Energy Engineering}

In addition, The Pennsylvania State University students may obtain a minor in energy engineering with 18 additional credits selected from a select group of courses. The minor in Energy Engineering is ideal for students who are interested in energy, have strong quantitative/mathematical skills, and who want to learn how to use this background to solve energy related engineering problems. The minor covers the fundamental principles of material and energy balances, thermodynamics, and fluid mechanics as applied to energy applications. Additional courses provide background in renewable and non renewable energy engineering concepts. The required courses will help students develop the necessary skills to understand, analyze and solve energy engineering problems, while providing a broad exposure to the full range of applications and opportunities available for engineers.

Agricultural and biological, chemical, civil, electrical, environmental, mechanical, mining, nuclear and petroleum engineering, materials science and engineering, industrial health and safety, and energy business and finance students will be able to substitute by petition some of their courses for some of the minor and dual or concurrent degree requirements.

\section{Courses for Energy Engineering Minor:}

\section{Three courses ( 9 credits) from the following}

EGEE 301 Thermodynamics and fluid mechanics of energy systems

EGEE 302 Principles of energy engineering

EGEE 304 Heat and mass transfer

EGEE 411 Energy Laboratory or EGEE 494A Research projects

EGEE 430 Introduction to combustion or ME 416 Introduction to combustion

EGEE 420 Hydrogen and fuel cells or ME 408 Fuel cell engines 


\section{Three courses ( 9 credits) from the following}

FSC 431 Chemistry of fuels- coal, petroleum, gas, biomass

FSC 432 Petroleum and natural gas processing

EGEE 433 Physical processes in energy engineering

EGEE 437 Fundamentals of renewable energy

EGEE 438 Sustainable energy options

EGEE 441 Electrochemical energy conversion

EGEE 451 Energy conversion processes: chemical and nuclear

EGEE 464W Energy design project or CH E 470 or ME 414 or Nuc E 430

EGEE 470 Air pollution from combustion sources or ME 470 Fundamentals of air pollution

\section{Current Status:}

This Major was approved and started just in fall 2007. Therefore, incoming students who applied long before were not informed about this Major through admission catalogues/brochures. By the end of 2007, the program has 15 students who declared Energy Engineering as their Major. The first class (Dual Majors) is expected to graduate in May 2009. The Department and the authors expect this to grow in the next year. This program will seek accreditation as a General Engineering Program by the Engineering Accreditation Commission of ABET in the near future. It is not currently accredited.

\section{REFERENCES}

1. USDOE Annual Energy Review 2006; DOE/EIA-0384(2006); 2007.

2. USDOE Annual Energy Outlook 2008; DOE/EIA-0383(2008); 2007. 